\title{
Does Length Limitation Promote Planning Activity during the Initial Planning Phase in L2 Essay Writing by University Students?
}

\author{
Hideyuki Sakihama
}

\begin{abstract}
The purpose of this study was to examine the effect of length limitation on the degree of planning activity, especially during the initial planning phase, in L2 essay writing. A total of 16 undergraduate and graduate students $(3$ males and 13 females, mean age $=20.75$ years, age range $=18-25$ ) participated in this study. All of them spoke Dutch (including Flemish) as their first language, and English as their second language. Participants took part in three sessions, in which they were asked to write an essay in English (L2) of 150 words, 300 words, and 600 words, respectively. All participants engaged in some kind of planning in the initial planning phase, and subsequently wrote the essay (writing phase). A questionnaire regarding planning activity and cognitive load was administered soon after finishing each phase. The results showed that (1) the degree of planning activity was highest in the 600-word condition, (2) the degree of planning activity was higher in the writing phase than in the initial planning phase, and (3) cognitive load was higher in the writing phase than in the initial planning phase.
\end{abstract}

Index Terms - Length limitation, planning activity, L2 essay writing.

\section{INTRODUCTION}

The purpose of this study was to examine the effect of length limitation on the degree of planning activity, especially during the initial planning phase, in L2 essay writing.

As Deane, Odendahl, Quinlan, Fowles, Welsh, and Bivens-Tatum [1] pointed out, writing, especially skilled writing, is a complex cognitive activity involving solving problems and deploying strategies to achieve communicative goals, and writers encounter challenges, for example, in planning, drafting, and revising activities. Rijlaarsdam and $\mathrm{H}$ van den Bergh [2] and $\mathrm{H}$. van den Bergh and Rijlaarsdam [3]-[5] had the same observations as Deane et al [1]. Several studies have been conducted to examine the effect of each of these activities on writing. For instance, H. van den Bergh and Rijlaarsdam [4] examined activities (mainly planning activities) during and before writing (drafting), and suggested that planning before writing (initial planning) is important for producing texts of higher quality. Ong [6] pointed out that engaging in some kind of planning before writing improves text quality because planning reduces the

Manuscript received October 20, 2017; revised March 12, 2018. This research was partly supported by the research grant of NWO (LIFT-project: number 6948)

Hideyuki Sakihama is with the Department of Economics, Hannan University, Matsubara, Osaka, Japan (e-mail:sakihama@hannan-u.ac.jp). cognitive demands of writers by making room for their limited working memory in the writing process. In contrast, Galbraith [7] pointed out that ideas were generated when writers wrote without planning and that the writing phase was more important than was the planning phase for generating ideas. This study was based on the idea of the importance of initial planning activity during writing, as reported by Ong [6].

Considering this aspect of planning, an important question is, "what is the best way of promoting the initial planning process?" Sakihama [8] attempted to answer this question by examining the effect of length limitation on Japanese expository text writing. He asked undergraduate and graduate students to write a text introducing Mauritania (an African country) to friends who were not familiar with it, in one of the following conditions: 200 characters (shorter length condition), 400 characters (normal length condition), and unlimited number of characters (unlimited condition). Results showed that the rate of important information (i.e., important facts about Mauritania) included in the text was highest in the 200-character condition. Additionally, regarding the writing process, all writers in the 200-character condition reported having engaged in some kind of planning regarding the content of the text before writing and experiencing difficulty in selecting information to be used in the text.

Based on this latter study, we generated two hypotheses to test in the present study: 1) the degree of planning activity in the initial planning phase will be highest in the shorter length condition, and 2) cognitive load in the initial planning phase will be highest in the shorter length condition.

However, there are some issues with Sakihama's study [8]. First, he set three conditions, but there was not a "longer length condition." To examine the effect of shorter length, it is necessary to include both shorter and longer length conditions in the experiment. Second, the writing process varied among writers. Although all writers in the 200-character condition first engaged in some kind of initial planning, this was not the case for the other two conditions. It is therefore necessary to design an experiment in which all writers engage in some kind of initial planning. Thirdly, there have been few studies examining the effect of length limitation on L2 writing. Thus, the effect of length limitation on L2 writing was examined in the present study.

Here are the research questions in this study:

RQ1: Is the degree of planning activity in the initial planning phase higher in the shorter length condition than in the longer length condition? 
RQ2: Is the degree of cognitive load in the initial planning phase higher in the shorter length condition than in the longer length condition?

To conduct this study, the length of the text (shorter, normal, and longer) and phase (initial planning phase, writing phase) were set as independent variables, and the degree of planning activity and cognitive load were set as dependent variables.

\section{METHODS}

\section{A. Participants}

A total of 16 undergraduate and graduate students in a Belgian university participated in this study. There were 3 male and 13 female students, with a mean age of 20.75 years (age range $=18-25$ ). Dutch (including Flemish) and English were their first and second languages, respectively. Their proficiency in English was CEFR(Common European Framework of Reference for Languages) B1 or higher. All participants engaged in initial planning activity before writing.

Participant recruitment was conducted in one of three ways; 1) recruitment at the beginning of the first lesson of an English grammar class in the second term of the 2015 academic year (in February 2016), 2) recruitment using Blackboard (a web-based classroom management system used at my university), or 3) recruitment based on participants' referral of their friends in the same course who were interested in this experiment. Regarding 1) and 2), I asked participants to fill out a consent form for participation if they were interested in the project. The purpose of this study (i.e., that one of my projects concerns the writing process of English as a second language), along with the requirements and stipend for participation (they were required to participate in three sessions on essay writing using a computer, after which would receive 50 euros), were spelled out in the form, and they were asked to voluntarily participate in this experiment.

\section{B. Materials}

Three kinds of materials were prepared for essay writing with the following titles: 1) "Working longer is bad for your mental health"; 2) "In order to get more women to the top level of companies we need to set quotas"; and 3) "Unemployment payment should be limited in time." They consisted of one sheet of size A4 paper with 9 to 16 items regarding the topic. Equality in terms of difficulty was confirmed by two researchers (including myself) who were familiar with this kind of research. There were three sessions per participant. Each participant used one piece of material per session, so the material they used differed depending on the session.

A crossword puzzle using words related to family was prepared for a thinking aloud (speaking aloud) activity during the initial planning phase. It consisted of horizontal and vertical lines (in total, nine words were included). All nine words were already filled in, so they were asked to explain the meaning (definition) of each word in the crossword puzzle by speaking aloud.
Questionnaires for the initial planning and writing phases were prepared and consisted of five questions on planning activity (Q1-Q5 regarding the initial planning phase, and Q9-Q13 regarding the writing phase), one question on writing (drafting) activity (Q6 for the initial planning phase and Q14 for the writing phase), one question on cognitive load (Q7 for initial planning phase and Q15 for writing phase), and one question regarding difficulty in writing (Q8 for the initial planning phase and Q16 for the writing phase). Questions on planning (Q1 to Q5 and Q9 to Q13) and writing (drafting) activities (Q6 and Q14) were originally based on those provided by Ong [6]. They were then compiled by two researchers (including myself) who were familiar with this kind of research to get exact responses from the participants regarding their likelihood to perform certain activities during the writing process. All questions were answered on a 5-point scale from 1 (strongly disagree) to 5 (strongly agree). There were 4,5 , or 8 additional questions according to the session regarding the difficulty of each topic, their opinion of the difference between writing in their first and second languages, and the length of the study period; the writing in their first and second languages, and their answers to questions Q1-Q5, Q9-Q13, Q7, and Q15 were used in the analysis.

\section{Conditions}

The following three length limitations in essay writing were set as study conditions: 150 words (shorter length condition), 300 words (normal length condition), and 600 words (longer length condition). The limitation of 300 words was set as the normal length condition based on the TOEFL Test of Written English. Subsequently, 150 and 600 words were set as the shorter and longer length conditions, respectively.

\section{Procedure}

There were three sessions in this experiment (one for each condition); thus, all participants took part in all three sessions. Experiments were conducted individually. Participants were asked to write one essay per session on a computer. The interval between sessions ranged from 1 day to 2 weeks. All sessions for each participant were completed within 1 month. The order of the conditions and materials was randomly assigned, and all participants experienced all conditions and used all materials by the end of the experiment. The instructions for the writing process were "think first, then write"; thus, participants were asked to engage in some kind of planning before writing, and then write (naturally, it was possible to do some amount of planning in the writing phase). Participants completed the questionnaires soon after finishing each phase. During the initial planning and writing phase, the entire writing (typing) process was recorded by Inputlog, introduced by Leijten and L. Van Waes [9], as well as a video camera, although the results of the above data analyses (Inputlog and video camera) were not used in this study.

As stated above, all of their activities from initial planning to the end of their writing phase were videotaped. I asked all of them to record their writing process only for academic purposes, and they all agreed to the recording. However, 
analyses of the data from the videotape were not utilized in this study.

\section{RESULTS AND DISCUSSIONS}

\section{A. Degree of Planning Activity}

First, the degree of planning was analyzed. There were five questions related to planning activities: idea generation (Q1/Q9), idea selection (Q2/Q10), idea elaboration (Q3/Q11), idea organization (Q4/Q12), and structure organization (Q5/Q13). In this study, the scores of questions Q1 to Q5 were combined, and the mean score was calculated. This also applied for questions Q9 to Q13. The mean score of Q1-Q5 was used to indicate the degree of planning activity in the initial planning phase, and that of Q9-Q13 was used to indicate the degree of planning activity in the writing phase. Table I shows the degree of planning activity in each condition and phase. A two-factor analysis of variance for a within-subjects design showed a main effect of condition (text length), $F(2,30)=10.71, p<.001$. Multiple comparisons (Bonferroni) showed that the degree of planning activity in the 600-word condition was higher than that in the 150-word and 300-word conditions. A main effect of phase was also observed, $F(1,15)=5.40, p<.05$, with the degree of planning activity in the writing phase being higher than in the initial planning phase. This implies that our first hypothesis (the degree of planning activity in the initial planning phase will be higher in shorter length condition) was not supported; thus, the answer to RQ1 (Is the degree of planning activity in the initial planning phase higher in the shorter length condition than in the longer length condition?) was negative.

TABLE I: DEGREE OF PLANNING ACTIVITY

\begin{tabular}{llll}
\hline \hline Condition/phase & Mean & SD & $\mathrm{N}$ \\
\hline 150 words & & & \\
Initial planning & 3.39 & 0.51 & 16 \\
Writing & 3.51 & 0.56 & 16 \\
300 words & & & \\
Initial planning & 3.45 & 0.64 & 16 \\
Writing & 3.88 & 0.78 & 16 \\
600 words & & & \\
Initial planning & 3.86 & 0.76 & 16 \\
Writing & 4.03 & 0.50 & 16 \\
\hline \hline
\end{tabular}

\section{B. Cognitive Load}

Second, the analysis of cognitive load was performed. Table II shows the mean scores of Q7 for the initial planning phase and Q15 for the writing phase in all three conditions. An analysis of variance showed a main effect of phase, $F(1,15)=11.52, p<.01$. Multiple comparisons (Bonferroni) indicated that the degree of cognitive load was higher in the writing phase than in the initial planning phase. However, there was no main effect of condition. This means that our second hypothesis (cognitive load in the initial planning phase will be highest in the shorter length condition) was not supported. Therefore, the answer to RQ2 (Is the degree of cognitive load in the initial planning phase higher in the shorter length condition than in the longer length condition?) was negative.
TABLE II: DEGREE OF COGNITIVE LOAD

\begin{tabular}{llll}
\hline \hline Condition/phase & Mean & SD & $\mathrm{N}$ \\
\hline 150 words & & & \\
Initial planning & 3.44 & 0.89 & 16 \\
Writing & 3.81 & 0.75 & 16 \\
300 words & & & \\
Initial planning & 3.38 & 1.09 & 16 \\
Writing & 4.13 & 0.50 & 16 \\
600 words & & & \\
Initial planning & 3.38 & 1.09 & 16 \\
Writing & 4.06 & 0.16 & 16 \\
\hline \hline
\end{tabular}

\section{Discussion}

As shown in sections 3.1 and 3.2, the two study hypotheses were not supported.

First, I will discuss the results regarding the degree of planning activity. In this study, the difficulty in writing in each condition did not differ significantly, and the main effect of condition on cognitive load was also not significant. Regardless of these results, the degree of planning activity was higher in the 600-word condition (longer length condition). The task used in this study was essay writing, and participants had to write their own opinions (for or against) certain topics and the reasons supporting their opinions. This format was the same in all conditions, but the amount of information and number of words differed according to the condition. Because of this kind of writing activity, participants might realize that the amount of information they could write was limited in the 150- and 300-word conditions, but not in the 600 -word condition. Thus, they might decide to write only main points in the shorter and normal length conditions, and add more information related to the main points in the 600-word condition. As a result, the degree of planning activity in both the initial planning and writing phases in the 150- and 300-word conditions would be lower than in the 600-word condition, as shown in the study.

Planning activity during the writing phase was higher than in the initial planning phase, which means that participants engaged in planning activity also in the writing phase. As Hayes [10] pointed out, there are complex interactions between sub-processes in the writing process. H. van den Bergh and Rijlaarsdam [4] indicated that some writers engage in planning activity during the writing phase. Galbraith [7] also pointed out the possibility of generating ideas during the writing phase. On the basis of these findings, it is likely that planning activity can also take place during writing.

It is important to discuss why the first hypothesis (the degree of planning activity in the initial planning phase in the shorter length condition will be higher than in the longer length condition) was not supported in this study. The major reason for this result might be participants' perception of the writing activity. As stated above, it is probable that writers do not think much about the information to be included in their text in the 150- and 300-word conditions because of the low number of words. If this were the case, writers' perspective on essay writing in this study would be different from that of Japanese undergraduate students, which will be further examined in my future studies. 
Regarding the results for cognitive load, this was higher in the writing phase than in the initial planning phase, which suggests that participants engaged in more activities in the writing phase. This is consistent with the process model of writing by Hayes [10]. However, it is necessary to consider why the answer to RQ2 (Is the degree of cognitive load in the initial planning phase higher in the shorter length condition than in the longer length condition?) was negative. Again, the possibility that writers thought less about the information they chose for their text in the shorter and normal length conditions might also explain the negative answer to RQ2.

\section{CONCLUSION}

This study examined the effect of the length of limitation on the degree of planning activity, especially during the initial planning phase, in L2 essay writing. Analyses of the questionnaires regarding planning and writing activities showed three main results: 1) the degree of planning activity was highest in the 600-word condition, 2) the degree of planning activity was higher in the writing phase than in the initial planning phase, and 3) the cognitive load was higher in the writing phase than in the initial planning phase.

In this study, only questionnaire answers were examined, which limits the precision of the examination of the writing process; therefore, I plan to examine other data collection processes in the future. Despite this limitation, the degree of planning activity in the longer length condition was found to be higher, which could be used to promote planning activity. Of course, this might be the case only for writers who "think first, then write"; therefore, the process of writers who combine planning and writing will be one of my future research projects.

\section{ACKNOWLEDGMENT}

This study was conducted during my sabbatical leave at the University of Antwerp in Belgium. The paper was written as a research accomplishment report for visiting researchers outside Japan at Hannan University during the academic year 2015. It was funded by Hannan University, and was also funded partly by the LIFT-project (number 6948) of FWO. I would like to express my gratitude to all of the staff at Hannan University and FWO, Prof. Dr. G. Rijlaarsdam, Prof. Dr. L. Van Waes, and their colleagues, who gave me the opportunity to conduct my research.

\section{REFERENCES}

[1] P. Deane, N. Odendahl, T. Quinlan, M. Fowles, C. Welsh, and J. Bivens-Tatum, Cognitive Models of Writing: Writing Proficiency as a Complex Integrated Skill, Research Report, ETS RR-08-55, October 2008.

[2] G. Rijlaarsdam, and H. Bergh, "The dynamics of composing - an agenda for research into an interactive compensatory model of writing: many questions, some answers," in The Science of Writing, C. M. Levy, and S. Ransdell, Eds. New Jersey: Lawrence Erbaum Associates, 1996, pp.107-125.

[3] H. Bergh and G. Rijlaarsdam, "The dynamics of idea generation during writing: an online study," in Studies in Writing: vol. 3, Knowing What to Write: Cognitive Perspectives on Conceptual Processes in Text Production, G. Rijlaarsdam and E. Esperet, Series Eds., M. Torrance, and D. Galbraith, Vol. Eds. Amsterdam: Amsterdam University Press, 1999, pp.99-120

[4] H. Bergh and G. Rijlaarsdam, "Changing in cognitive activities during the writing process and relationship with text quality," Educational Psychology., vol. 21, no. 4, pp. 374-385, July 2001

[5] H. Bergh and G. Rijlaarsdam, "The dynamics of idea generation during writing: an online study," in Studies in writing: Vol. 20, Writing and Cognition: Research and Application, G. Rijlaarsdam, Series Ed, M. Torrance, L. Van Waes, and D. Galbraith, Vol. Eds. Amsterdam: Elsevier, 2007, pp. 125-150.

[6] J. Ong, "How do planning time and task conditions affect metacognitive processes of L2 writers?" Journal of Second Language Writing, vol. 23, pp. 17-30, March 2014.

[7] D. Galbraith, "Writing as a knowledge-constituting process," in Studies in Writing: Vol. 4, Knowing What to Write: Conceptual Processes in Text Production, M. Torrance and D.Galbraith, Eds. Amsterdam: Amsterdam University Press, 1999, pp. 139-160.

[8] H. Sakihama, "Does a length limitation promote better expository writing?" Japanese Journal of Educational Psychology, vol. 53, no. 1, pp. 62-73, March 2005.

[9] M. Leijten and L. Waes, "Keystroke logging in writing research: Using Inputlog to analyze and visualize writing processes," Written Communication, vol. 30, no. 3, pp. 358-392, June 2013.

[10] J. R. Hayes, "A new framework for understanding cognition and affect in writing," in The Science of Writing, C. M. Levy and S. Ransdell, Eds. New Jersey: Lawrence Erbaum Associates, 1996, pp. 1-27.

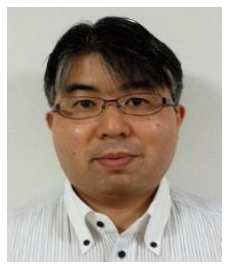

Hideyuki Sakihama was born in Kobe (Japan) on August 18, 1973. He received his B.A. degree at Osaka Kyoiku University and the Ph.D. degree at Nagoya University in Japan in the field of educational psychology. He is now a professor in the Department of Economics at Hannan University in Osaka, Japan.

His research areas are 1) the writing process of college students in first and second languages, and 2) how to cultivate skills among college students for becoming school teachers in teaching profession courses.

Dr. Sakihama is a member of the Japanese Association of Educational Psychology and the Japan Association of Psychology of Teaching and Learning. 